\title{
PRIVATIZAÇÃo E EFICIÊNCIA DAS USINAS HIDRELÉTRICAS BRASILEIRAS
}

\author{
Luciano Menezes Bezerra Sampaio ${ }^{\S}$ \\ Francisco S. Ramos ${ }^{\text {a }}$ \\ Yony Sampaio ${ }^{\dagger}$
}

\begin{abstract}
RESUMO
A transição do setor elétrico brasileiro do modelo estatal para o privado visa garantir recursos para construção de novas usinas, reduzir os riscos de déficit de energia elétrica, eliminar desperdícios do sistema gerador atual e aumentar sua produtividade. Para analisar os mecanismos da gestão das usinas hidrelétricas, determinou-se o grau de eficiência técnica das usinas hidrelétricas brasileiras por meio da metodologia de Análise de Envoltória de Dados (DEA). A análise foi feita sobre 71 usinas hidrelétricas. Os escores de eficiência foram analisados segundo: o tipo de propriedade da empresa - pública ou privada; a empresa a qual pertencem as hidrelétricas; a localização, segundo a bacia hidrográfica; o tamanho, sob o aspecto de potência instalada; a altura de queda; e a mão-de-obra. O setor público foi mais eficiente que o privado. Destaca-se a CESP (empresa pública estadual) e a Light (empresa privada) com, respectivamente, o melhor e o pior desempenho de eficiência. As hidrelétricas mais eficientes quanto à potência instalada foram as intermediárias, e quanto à localização foram as da bacia do rio Paraná.
\end{abstract}

Palavras-chave: usinas hidrelétricas, eficiência, DEA.

\begin{abstract}
The Brazilian electrical sector is being privatized with the objectives of guaranteeing funds for the construction of new power plants, reducing the risks of energy deficits, eliminating wastes of the present generating units and increasing its productivity. To evaluate the performance of existing hydroelectric power plants the technical efficiency of Brazilian hydroelectric power plants was determined using Data Envelopment Analysis (DEA). The analysis included 71 hydroelectric power plants, all with more than $50 \mathrm{MW}$ capacity. The efficiency scores were analyzed according to the following criteria: type of ownership - private or public (state or federal government); company; location - river basin; and the three inputs used in the analysis: size, in relation to generating capacity; water level difference; and manpower. Public plants were more efficient than private ones. Cesp (state government company) had the best performance and Light (private company) had the worst one. According to generating capacity, intermediate size plants were the most efficient and according to river basin, those of the Paraná river were the most efficient.
\end{abstract}

Key words: power plants, hydroelectric, efficiency, DEA.

JEL classification: N56, Q00.

$\S$ Doutorando em Economia pelo PIMES-UFPE e Universidade de Paris I, filiado ao Departamento de Economia / PIMES, Universidade Federal de Pernambuco.1samp@hotmail.com.fr.

a Doutor pelo CORE, Universidade Católica de Louvain, filiado ao Departamento de Economia / PIMES, Universidade Federal de Pernambuco e bolsista do CNPq. fsr@ufpe.br.

$\dagger \quad$ Ph.D. pela Universidade da Califórnia, filiada ao Departamento de Economia / PIMES, Universidade Federal de Pernambuco e bolsista do CNPq. ysampaio@elogica.com.br.

Recebido em março de 2004. Aceito em março de 2005. 


\section{INTRODUÇÃo}

As previsões de crescimento econômico do Brasil para os próximos anos, em torno de 3\%, trazem como conseqüência a necessidade de expansão do setor gerador de energia elétrica. $\mathrm{O}$ governo estimou a necessidade de aumento da capacidade instalada do setor elétrico em quase 40\%, de 1998 até 2003. Destacam-se os investimentos na construção de termelétricas visando suprir o aumento na demanda de energia a curto prazo, já que a execução destes projetos é rápida. E pensando a longo prazo, o plano de expansão das hidrelétricas - principal forma de geração de energia do País - já conta com 470 locais em projeto ou em fase de construção de usinas. (SIPOT, 1998). Com isto, o governo pretende minimizar o risco de déficit de energia elétrica que ultrapassa o limite superior, compatível com o sistema elétrico brasileiro. Foi também tomada a decisão de reformular o setor.

No início do século XX, o sistema brasileiro era essencialmente privado e baseado no ato de concessão cedida às empresas pelo poder público, que podia ser representado pelo governo federal, estadual ou municipal, dependendo da natureza e abrangência do processo. Àquela época destacavam-se a empresa canadense Light, que atuava em São Paulo e Rio de Janeiro, e a Amforp - empresa americana - que iniciou suas atividades no Brasil em 1927, adquirindo várias empresas brasileiras num período muito curto, e obtendo concessões para atuar no interior paulista e em várias capitais, incluindo Recife, Salvador, Natal e Maceió.

Com a Segunda Guerra Mundial (1939-1945), os serviços de eletrificação foram se deteriorando, e junto à crescente insatisfação da população e ao desequilíbrio da oferta e demanda de energia acirraram-se as críticas às principais empresas do setor elétrico, sendo a Light o principal alvo das reclamações.

A situação era realmente drástica, visto que a demanda continuava a crescer nas áreas já servidas e aumentava o apelo por extensão dos serviços às áreas não atendidas. Em todas as regiões do País ocorriam racionamentos constantes para equilibrar a demanda efetiva à capacidade instalada, que teve seu ritmo de crescimento bastante reduzido até 1945.

Várias tentativas isoladas sucederam-se para solucionar o problema da escassez de energia, dentre as quais se destacam a criação da Companhia Hidrelétrica do São Francisco - CHESF - e a criação da empresa Centrais Elétricas de Minas Gerais S.A - CEMIG -, em 1952. Apesar disso, a demanda potencial crescia acima da potência instalada.

Além da necessidade óbvia de expansão da capacidade instalada, após anos de discussão, chegava-se à conclusão que o sistema elétrico utilizado até então era ineficiente, e começava-se a desenhar um novo cenário, com a reformulação do setor, baseado em dois pontos:

- a interligação dos sistemas existentes;

- a estatização de hidrelétricas particulares e da Amforp.

O primeiro ponto diz respeito à tentativa de melhorar a eficiência do sistema elétrico brasileiro. Para tanto, foi autorizada a criação da Centrais Elétricas Brasileiras S.A. (Eletrobrás) pelo Congresso, em 1961, sendo a ela incorporadas as empresas Chesf e Furnas (criada em 1957), que responderiam pela interligação dos sistemas elétricos no Nordeste e Sudeste, respectivamente. Seriam criadas posteriormente, com a mesma função da Chesf e de Furnas, outras duas subsidiárias - a Eletrosul, em 1968, na região Sul, e a Eletronorte, em 1973, na região Norte. Completando o quadro de empresas controladas pela Eletrobrás, constituiu-se, em 1974, a Itaipu Binacional, com iguais participações no capital, por parte da Eletrobrás e da ANDE, sendo esta última a entidade responsável pelos serviços de energia elétrica no Paraguai. 
A Eletrobrás, por meio dessas empresas adquiridas, também foi incumbida da expansão do quadro gerador, com a construção de novas hidrelétricas e a aquisição de diversas usinas particulares nas regiões onde suas subsidiárias atuavam.

Ao final da década de 1970 tem-se, com a compra pelo governo brasileiro das ações da Light, em 1979, um quadro em que todas as concessionárias do setor de energia elétrica tinham capital nacional.

Apesar de todas as aquisições feitas pela Eletrobrás, a crescente demanda por energia exigia a expansão da capacidade instalada nacional por meio da construção de novas usinas hidrelétricas, o que foi feito com a execução de grandes projetos. Em apenas duas décadas - de 1960 a 1980 - entraram em operação 15 novas usinas.

A economia evoluiu seguindo previsões otimistas de crescimento, paralelamente à confirmação das elevadas expectativas de consumo de energia até 1980. A partir daí, as previsões de demanda foram frustradas até o ano de 1990. Os principais motivos foram os investimentos imprudentes, realizados pelo governo, na construção de algumas das inúmeras hidrelétricas realizadas nos anos anteriores e o segundo choque de petróleo associado à elevação das taxas de juros no início da década de 1980 .

Estabeleceu-se nova crise no setor, com usinas enormes, inacabadas, e falta de recursos para manter o plano de expansão. Isto levou, em 1985, num tumultuado ambiente econômico e político, após a morte do presidente Tancredo Neves, à elaboração do Plano de Recuperação Setorial, com a participação do Ministério das Minas e Energia.

A partir de então, várias iniciativas foram tomadas, embora em um cenário de grande escassez de recursos para construção de hidrelétricas, com vistas a ampliar o quadro gerador hídrico nacional que cada vez mais se consolida como a principal fonte de geração de energia elétrica no Brasil.

Essa tão mencionada escassez de recursos e o temor de uma crise de abastecimento de energia, que realmente se concretizou em 2000, levaram o governo Fernando Henrique Cardoso a investir numa solução ambiciosa: a privatização do setor de energia elétrica, incluindo as empresas de geração. Esta intenção é comprovada com a inclusão dos ativos federais da geração no Programa Nacional de Desestatização (PND).

Optou-se por manter o sistema de despacho de carga centralizado, sendo criada uma associação civil responsável pela determinação da quantidade de energia a ser produzida por cada hidrelétrica brasileira - o Operador Nacional do Sistema (ONS) -, sendo seus integrantes as empresas de geração, transmissão, distribuição, importadores e exportadores de energia elétrica, e consumidores livres, tendo o Ministério das Minas e Energia como participante.

Para garantir que toda esta energia determinada pela ONS seja disponibilizada para os centros de consumo, o sistema interligado de transmissão do Brasil permanecerá sob controle do governo federal, pelo menos em um primeiro momento, devendo as empresas de distribuição de energia pagar por seu uso. Ou seja, estão sendo privatizadas as empresas dos setores de geração e distribuição de energia elétrica, continuando estatal o sistema que liga estes dois - o sistema de transmissão. No final de 1996, foi criada a Agência Nacional de Energia Elétrica - ANEEL como órgão autônomo, com objetivo de ser o principal regulador do setor.

A perspectiva deste novo modelo é a tentativa de equilíbrio entre oferta e demanda de energia elétrica, por meio da captação de recursos e da busca do aumento de eficiência do sistema como um todo, com a introdução de competitividade. O montante necessário para assegurar o aumento da capacidade instalada nos anos de 1998 a 2002, em algumas previsões, chegava a quase 36 bilhões de dólares. 
No que concerne aos ganhos de eficiência, é fundamental eliminar desperdícios e aumentar a produtividade do sistema como um todo, da geração à distribuição de energia. Em geral, os programas brasileiros de combate ao desperdício sempre foram voltados para os consumidores, na tentativa de reduzir consumo e evitar perdas de energia elétrica no seu uso final. Com a privatização das empresas do setor elétrico, e a expectativa de um mercado competitivo para geração e distribuição, o enfoque da eficiência torna-se uma ótima estratégia, do ponto de vista empresarial, para reduzir custos e aumentar sua margem de lucro ou, alternativamente, repassar os ganhos com o aumento da eficiência para o preço de seus produtos, reduzindo-os e ampliando o seu número de consumidores.

O enfoque deste trabalho é no setor gerador. Acredita-se que as empresas deste setor, até pouco tempo todas estatais, podem vir a aprimorar em muito seus sistemas produtivos, obtendo ganhos significativos, com o aumento da eficiência, na quantidade ofertada de energia elétrica, pois se há uma redução na quantidade dos insumos utilizados, o excedente dos mesmos pode ser deslocado para a nova esfera produtiva, possibilitando o aumento da produção de energia. Além de poder promover uma redução no preço final da energia elétrica, a melhora da eficiência na geração da energia pode diminuir a necessidade de expansão e os correspondentes investimentos no setor.

Como se tem no Brasil um sistema de produção de energia elétrica com mais de $95 \%$ da energia gerada por usinas hidrelétricas, optou-se por analisar este segmento da geração com o objetivo geral de verificar de que forma as Usinas Hidrelétricas (UHEs) brasileiras estão operando no que se refere à correta alocação de recursos, ou seja, pretende-se determinar o grau de eficiência técnica das usinas hidrelétricas brasileiras.

O trabalho está estruturado em três seções, além dessa introdução: a metodologia utilizada, os resultados obtidos e o significado dos mesmos e as conclusões.

\section{Metodologia}

O grau de eficiência das usinas hidrelétricas foi determinado utilizando-se o método DEA (data envelopment analysis, isto é, análise de envoltória de dados). Neste método, as usinas hidrelétricas são consideradas DMUs (decision making units, ou unidades de tomada de decisão), que são avaliadas por suas eficiências relativas, ou seja, aquelas DMUs eficientes são identificadas como componentes da fronteira tecnológica, e as demais, ditas ineficientes, têm seu grau de eficiência medido em relação à fronteira.

De acordo com a forma da fronteira, têm-se duas abordagens distintas - a paramétrica e a não-paramétrica. No primeiro caso, postula-se que a fronteira do conjunto produtivo pode ser representada por uma função de produção caracterizada por parâmetros constantes. Este método foi utilizado, pioneiramente, por Aigner e Chu (1968). Com isso, uma forma funcional é definida $a$ priori para a tecnologia, e a estimação é feita, normalmente, por meio de métodos econométricos. A especificação da função de produção é a maior limitação da abordagem paramétrica. As medidas de eficiência podem variar muito segundo a função escolhida. Esta é justamente a diferença principal entre as duas abordagens.

A não-paramétrica não se baseia em uma função especificada a priori. A forma da fronteira do conjunto produtivo é determinada considerando-se que o conjunto de produção deve satisfazer determinadas propriedades. O método DEA está inserido na abordagem não-paramétrica, e emprega o uso de métodos de programação matemática para estimar modelos de fronteiras de produção e obter os escores de eficiência. Este método é baseado no trabalho de Farrell (1957) e permite consi- 
derar múltiplos insumos e produtos. As DMUs realizam tarefas similares e se diferenciam pelas quantidades dos insumos que consomem e dos produtos que resultam. Na utilização deste método, supõe-se que o conjunto de possibilidade de produção, como se mencionou anteriormente, deve satisfazer determinadas propriedades, ou seja, não há suposições sobre a fronteira propriamente dita.

Este conjunto de produção é limitado pela fronteira de produção composta por aquelas DMUs que são eficientes. A determinação das DMUs eficientes é feita por meio da resolução, para cada uma delas, de um sistema de equações lineares definido para mensurar o nível de eficiência de cada DMU.

Foram utilizados o modelo CCR (Charnes, Cooper e Rhodes, 1978), que foi o primeiro modelo DEA a partir do qual essa metodologia iria se desenvolver, e que assume retornos constantes de escala, e o modelo BCC (Banker, Charnes e Cooper, 1984), posteriormente desenvolvido, que assume retornos variáveis de escala. Estes modelos são também conhecidos, respectivamente, por DEA-C e DEA-V. Os índices de eficiência das hidrelétricas utilizando ambos os modelos foram obtidos por meio do software DEAP Computer Program. (Coelli, 1996).

O ponto crucial na metodologia de avaliação da eficiência das usinas hidrelétricas é a escolha adequada das variáveis que serão consideradas para este fim, mais precisamente aquelas que representarão os insumos que resultam na produção de energia.

\subsection{Amostra}

Os dados correspondentes às variáveis consideradas neste trabalho são, na maioria, de origem da Eletrobrás, mais especificamente do seu Sistema de Informação do Potencial Hidrelétrico Brasileiro - SIPOT -, referente ao ano de 1998. Nesta fonte, há informações sobre 126 hidrelétricas em operação, com potência instalada individual superior a $10 \mathrm{MW}$. O fator responsável pela maior redução da amostra foi a ausência de dados referentes à produção de energia para usinas com potência inferior a $50 \mathrm{MW}$, uma vez que este dado foi obtido do Operador Nacional do Sistema Elétrico - ONS, que é responsável pela determinação da produção de energia de usinas com capacidade superior a este valor. Não foi possível obter com as empresas a produção de energia das hidrelétricas com potência instalada entre 10 e $50 \mathrm{MW}$. Também foi excluída da amostra a hidrelétrica de Itaipú, que, por ser binacional, não é "despachada” pelo ONS. Outro fator é a aglomeração de algumas usinas que o ONS faz na determinação das cotas de energia, ou seja, realiza a determinação considerando um complexo de usinas, como, por exemplo, a consideração das usinas Paulo Afonso 1, 2 e 3 como uma única unidade.

Foi feita, ainda, uma análise cuidadosa das informações disponíveis no SIPOT, confrontandoas com as informações dos "sites" das empresas sobre todas as hidrelétricas consideradas, dando-se preferência às últimas, em caso de discordância.

Depois da exclusão das usinas com potência inferior a $50 \mathrm{MW}$, e feitas algumas aglomerações segundo o modelo do ONS, obteve-se uma base de dados de 71 hidrelétricas, ou melhor, de 71 unidades produtivas, pertencentes a 12 empresas. As empresas Centrais Elétricas de Cachoeira Dourada S.A. (CDSA), Empresa Metropolitana de Águas e Energia S.A. (EMAE), Espírito Santo Centrais Elétricas S.A. (ESCELSA) e a Centrais Elétricas do Norte do Brasil (ELETRONORTE) contribuíram com apenas uma unidade de produção cada. A Companhia Estadual de Energia Elétrica S.A. (CEEE) e a Centrais Geradoras do Sul do Brasil S.A. (GERASUL) foram representadas por três hidrelétricas cada. A Companhia Paranaense de Energia (COPEL), por quatro. A Light Serviços de Eletricidade S.A. (LIGHT), por seis. A Companhia Hidro Elétrica do São Francisco 
(CHESF), por sete unidades produtivas. Centrais Elétricas S.A. (FURNAS), por nove usinas. A Companhia Hidrelétrica de Minas Gerais (CEMIG), por doze. E a Companhia Energética de São Paulo (CESP), por vinte e três.

\subsection{Variáveis indicadas e consideradas}

O presente trabalho procurou definir um conjunto de variáveis capazes de caracterizar adequadamente o funcionamento de uma usina hidrelétrica e que pode influenciar na eficiência de cada uma delas. Devido à impossibilidade de obter, da maioria das empresas do setor elétrico brasileiro, os dados requisitados, não foi possível usar, no cálculo de eficiência das hidrelétricas, todas as variáveis julgadas importantes. A pretensão era obter um escore de eficiência para cada usina, considerando como único produto um valor médio anual de energia elétrica produzida. Como insumos seriam utilizadas as seguintes variáveis: a potência instalada; a altura líquida (ou efetiva); a vazão turbinada; a mão-de-obra envolvida direta e indiretamente na produção e manutenção da usina. Outra alternativa seria a consideração de todas as variáveis citadas, com exceção da última, que seria incluída numa nova variável representativa dos custos com a manutenção e a operação. Dado um determinado nível de produção de energia, a potência instalada é a variável que representa o uso da capacidade de produção de uma usina, e mede, assim, a adequação do projeto da hidrelétrica. Para o mesmo nível de produção de energia, a altura líquida e a vazão turbinada expressam a maneira como está sendo feito o uso da água. Acredita-se que a melhor forma de analisar o uso da água é por meio do produto destas duas variáveis - vazão e altura -, já que a potência produzida numa usina pode ser expressa em função deste mesmo produto. Com relação à mão-deobra, analisa-se a eficiência em relação ao trabalho empregado na atividade produtiva.

Devido ao problema de obtenção de dados, foi feita uma redução no número das variáveis utilizadas, que representam os insumos, para a obtenção do produto - média anual de energia elétrica produzida. Desta forma, foram consideradas as seguintes variáveis referentes aos insumos: a potência instalada; uma aproximação da altura líquida, chamada, de agora em diante, de altura de queda; e uma estimativa da mão-de-obra utilizada na operação e manutenção direta e indiretamente. A seguir, detalham-se as diversas variáveis selecionadas, sendo a primeira referente ao produto, e as demais, aos insumos.

\section{a) Energia produrida}

Como produto foi utilizada a energia média anual produzida, referente ao ano de 1999. Esse dado foi disponibilizado pelo Operador Nacional do Sistema Elétrico - ONS, que passou a "despachar", ou seja, determinar quanto cada usina brasileira, com capacidade instalada acima de 50 MW (e ainda três hidrelétricas com potência instalada abaixo deste valor), deve produzir mensalmente. Com os valores mensais foi determinada uma média anual. O primeiro ano em que a ONS determinou esses valores foi o de 1999 e, de acordo com a mesma instituição, esses valores foram determinados, segundo a mesma metodologia usada anteriormente pela Eletrobrás, para maximizar a produção de energia elétrica do sistema como um todo. Esse fato é importante, já que há dados referentes ao ano de 1998.

\section{b) Potência instalada}

A potência instalada é a capacidade máxima de produção de uma usina hidrelétrica, ou seja, é a quantidade máxima de energia que pode ser produzida numa hidrelétrica, numa determinada unidade de tempo. Do ponto de vista da eficiência, deve-se ter a máxima produção de energia de- 
terminada pela potência instalada. Analisar a quantidade de energia produzida de acordo com a potência instalada é verificar se se está usando a capacidade produtiva de uma hidrelétrica. Se uma usina tem uma determinada capacidade instalada ociosa, ela não está sendo eficiente no uso de seu potencial. A unidade usada para esta variável é o MW. As potências instaladas de todas as usinas brasileiras em operação estão disponíveis no Sistema de Informação do Potencial Hidrelétrico Brasileiro (1998) - SIPOT -, da Eletrobrás. Quando os valores de potências instaladas do SIPOT diferiram dos encontrados nos sites das empresas que operam estas usinas, optou-se por usar os dados das próprias empresas.

\section{c) Mão-de-obra}

O trabalho é básico para a obtenção de qualquer produto. É eficiente a empresa que utiliza menos quantidade de trabalho para obter uma unidade de energia ou que com uma dada quantidade de trabalho obtém a maior quantidade de energia.

A maioria das empresas não forneceu este dado. Considera-se, no entanto, que o motivo é a dificuldade em determinar o número de funcionários que trabalham direta e indiretamente na geração hídrica de cada empresa e, mais especificamente, em cada usina hidrelétrica, uma vez que quase todas as companhias atuam em mais de um setor ligado a energia elétrica (os mais comuns geração, transmissão e distribuição) e mantêm funcionários em comum, principalmente em escritórios. Além deste fato, há ainda algumas empresas que trabalham apenas com geração elétrica, enquanto outras, além de gerar energia por meio de hidrelétricas, têm em seu quadro usinas termelétricas. Uma terceira dificuldade relevante é que algumas empresas têm equipes de empregados responsáveis pela manutenção de várias usinas hidrelétricas, o que impede a contabilização direta da mão-de-obra de cada usina. Por todos esses motivos, foi feita uma estimativa do número de funcionários, de acordo com informações gerais levantadas nas empresas e, posteriormente, determinou-se um critério para dividir a mão-de-obra de cada empresa por suas hidrelétricas, baseando-se na consulta a técnicos da área, como explicado a seguir.

Primeiro, consultando técnicos das diversas empresas que atuam em mais de um setor ligado à energia elétrica ou daquelas que geram energia por hidrelétricas e termelétricas, estimou-se um porcentual do número total de funcionários que atuam na geração hídrica. O número total de funcionários de cada empresa do setor de energia elétrica é referente ao ano de 1998 e está disponível na publicação conjunta da UFRJ e Eletrobrás de título Séries 1999. (Eletrobrás e UFRJ, 1999).

De posse desse porcentual, foi alocada a cada hidrelétrica o número de funcionários proporcional ao número de turbinas de cada usina. Essa aproximação ameniza a questão de uma equipe responsável pela manutenção de mais de uma hidrelétrica, e é fundamentada na argumentação de técnicos da área de manutenção que acreditam ser a melhor forma de alocação, já que, segundo eles, o tempo de reparo e manutenção de uma turbina é mais ou menos o mesmo, independente do seu tipo (turbina Pelton, Francis ou Kaplan) e de sua potência, dado o tamanho das hidrelétricas da amostra.

\section{d) Altura de queda}

A altura líquida de queda é a altura bruta menos as perdas de altura causadas pelas grades, entrada da adutora, válvulas, redução de diâmetro, curvas etc., e perdas por atrito nas paredes da adutora. Dada uma mesma altura de queda, a hidrelétrica será tanto mais eficiente quanto mais energia gerar, mantidas as outras variáveis constantes. A altura bruta é medida, em metros, pela diferença entre as elevações da linha energética a montante e a jusante, ou seja, é a diferença entre os níveis de água a montante e a jusante, com as respectivas correções devidas às alturas cinéticas nas 
duas seções consideradas. O nível de água de montante é o da bacia e o de jusante o do canal de descarga.

Como a maioria das empresas não disponibilizou esses dados, foi feito um cálculo aproximado para a altura bruta, considerando como nível de água de montante uma média entre os níveis máximos e mínimos de montante de cada usina hidrelétrica. Da mesma forma foram calculados os níveis de jusante. As correções devido às alturas cinéticas, que implicam uma pequena variação dos valores da queda bruta, foram desprezadas. Em seguida, de posse das perdas médias de cada usina, calculou-se esta aproximação para a altura líquida, definindo-a como a altura de queda, dada em metros. A análise da produção de energia com relação a esta variável representa o modo como as usinas usam a água. Vale relembrar aqui a limitação de usar apenas a altura de queda em vez do produto da altura efetiva pela vazão turbinada. Quanto menor a quantidade de água usada por uma usina para atingir um nível estabelecido de produção de energia, mais eficiente será esta usina.

Os dados envolvidos na determinação desta aproximação para a altura líquida estão disponíveis no Sistema de Informação do Potencial Hidrelétrico Brasileiro (1998) - SIPOT -, da Eletrobrás.

\section{Resultados E Discussões}

\subsection{Eficiência global}

Um menor número de hidrelétricas apresentou o nível máximo de eficiência no método DEA-C do que no método DEA-V. No DEA-C, cinco hidrelétricas atingiram eficiência máxima (7,0\% do total). Esse baixo porcentual reflete as hipóteses mais restritivas assumidas por essa abordagem, mais especificamente a hipótese de retornos constantes de escala imposta sobre o Conjunto de Possibilidades de Produção (CPP). Já no DEA-V, 21 hidrelétricas foram apontadas como eficientes (29,6\% do total), o que mostra a aproximação da fronteira devido à consideração de retornos variáveis de escala.

Houve uma correlação significativa entre os escores de eficiência das hidrelétricas e o ordenamento segundo estes escores, nos dois métodos usados. Sugere-se a aplicação de outras metodologias não-paramétricas e paramétricas que permita uma comparação mais ampla dos resultados. Dada a heterogeneidade de tamanho das hidrelétricas e a presença de distintas tecnologias, a hipótese de retornos variáveis parece ser a mais adequada. Mesmo observando apenas os resultados do DEA-V, que indica uma quantidade maior de usinas eficientes, constata-se grande número de usinas hidrelétricas abaixo da fronteira eficiente.

Apesar da relação entre os ordenamentos dos métodos ser esperada, já que ambos pertencem à mesma metodologia DEA, podem ser revelados alguns fatos importantes sobre a situação das hidrelétricas tidas como mais e menos eficientes.

As usinas tidas como eficientes pela metodologia DEA-C também o são para a metodologia DEA-V. Conseqüentemente, pode-se afirmar com segurança que as cinco hidrelétricas tidas como eficientes para o DEA-C obtiveram um desempenho superior às outras.

A Tabela 1 agrupa as quinze hidrelétricas mais eficientes no método DEA-C. Dentre elas, onze foram classificadas com eficiência máxima no DEA-V (que apresentou 21 usinas com escore igual à unidade). 


\section{Tabela 1 - Quinze hidrelétricas mais eficientes, segundo o modelo DEA-C}

\begin{tabular}{lcc}
\hline Usinas Hidrelétricas & \multicolumn{2}{c}{ Escore de eficiência } \\
\cline { 2 - 3 } & DEA-C & DEA-V \\
\hline Jaguara & 1,000 & 1,000 \\
São Simão & 1,000 & 1,000 \\
Nilo Peçanha (Nilo Peçanha 1) & 1,000 & 1,000 \\
Xingo & 1,000 & 1,000 \\
Tucuruí (Tucuruí 1) & 1,000 & 1,000 \\
Jupiá (Eng. Souza Dias) & 0,945 & 1,000 \\
Salto Grande (Lucas Nogueira Garcez) & 0,944 & 1,000 \\
Porto Colômbia & 0,932 & 1,000 \\
Rosana & 0,910 & 1,000 \\
Mascarenhas de Moraes & 0,906 & 0,923 \\
Capivara (Esscola de Eng. Mackenzie) & 0,879 & 0,894 \\
Água Vermelha (José Ermírio de Moraes) & 0,877 & 0,884 \\
Jurumirim (Armando A. Laydner) & 0,866 & 1,000 \\
Canoas I & 0,865 & 1,000 \\
Volta Grande & 0,849 & 0,901 \\
\hline
\end{tabular}

As dez outras hidrelétricas classificadas com escore igual a um, pelo DEA-V, e que não estão entre as quinze da tabela acima, tiveram um ordenamento o mais diversificado possível no DEAC, obtendo, na maioria, péssima classificação neste último método.

\subsection{Decompondo a eficiência}

Os escores de eficiência das hidrelétricas foram analisados segundo os seguintes critérios: o tipo de propriedade da empresa - pública (estadual ou federal) e privada; a empresa a qual pertencem as hidrelétricas; a localização segundo a bacia hidrográfica; e ainda em relação as três variáveis consideradas no trabalho como insumos: o tamanho, sob o aspecto de potência instalada (uma proxy para o capital); a altura de queda; e, finalmente, a mão-de-obra.

\subsubsection{Eficiência e propriedade (privada ou pública)}

$\mathrm{Na}$ amostra considerada, 59 hidrelétricas $(83,1 \%)$ são pertencentes às empresas públicas e 12 $(16,9 \%)$ à iniciativa privada. As 59 usinas hidrelétricas públicas podem ser subdivididas em federais e estaduais, sendo 17 pertencentes à primeira subdivisão e as 42 restantes à segunda.

No DEA-C, 70,7\% das usinas federais tiveram escores maior que 0,6, enquanto 59,5\% das públicas estaduais e $41,6 \%$ das usinas do setor privado alcançaram escore acima deste valor. 
Pelo DEA-V (Tabela 2), 52,9\% das usinas federais se localizaram nas duas classes mais altas de eficiência, contra $66,7 \%$ das estaduais e $50 \%$ das privadas. Ou seja, nestas duas classes conjuntas, o setor público estadual obteve melhor rendimento porcentual que os demais setores.

Tabela 2 - Distribuição dos escores de eficiência técnica, segundo a propriedade: modelo DEA-V

\begin{tabular}{|c|c|c|c|c|c|c|}
\hline \multirow[t]{2}{*}{ Classe de Eficiência Técnica } & \multicolumn{2}{|c|}{ Pública Federal } & \multicolumn{2}{|c|}{ Privada } & \multicolumn{2}{|c|}{ Pública Estadual } \\
\hline & $\begin{array}{l}\text { Número de } \\
\text { hidrelétricas }\end{array}$ & $\%$ & $\begin{array}{l}\text { Número de } \\
\text { hidrelétricas }\end{array}$ & $\%$ & $\begin{array}{l}\text { Número de } \\
\text { hidrelétricas }\end{array}$ & $\%$ \\
\hline $0-<0,2$ & 0 & 0,0 & 0 & 0,0 & 0 & 0,0 \\
\hline $0,2-<0,4$ & 0 & 0,0 & 0 & 0,0 & 0 & 0,0 \\
\hline $0,4-<0,6$ & 2 & 11,8 & 2 & 16,7 & 6 & 14,3 \\
\hline $0,6-<0,8$ & 6 & 35,3 & 4 & 33,3 & 8 & 19,0 \\
\hline $0,8-<1$ & 4 & 23,5 & 1 & 8,3 & 17 & 40,5 \\
\hline 1 & 5 & 29,4 & 5 & 41,7 & 11 & 26,2 \\
\hline Total & 17 & 100,0 & 12 & 100,0 & 42 & 100,0 \\
\hline
\end{tabular}

A Tabela 3, no entanto, aponta características distintas entre as médias dos dados correspondentes às variáveis consideradas para as hidrelétricas dos três tipos de propriedade considerados.

Tabela 3 - Média das variáveis consideradas para os setores privado, público estadual e público federal

\begin{tabular}{lccc}
\hline Variáveis Consideradas & \multicolumn{3}{c}{ Médias das variáveis por setor } \\
\cline { 2 - 4 } & Privado & P. Estadual & P. Federal \\
\hline Energia produzida (MW) & 233 & 290,57 & 707 \\
Potência instalada (MW) & 447 & 526,56 & 1324 \\
Altura de queda (m) & 182 & 67,73 & 62 \\
Mão-de-obra ( $\mathrm{n}^{\circ}$ de funcionários) & 152 & 255,5 & 281 \\
\hline
\end{tabular}

As hidrelétricas federais são, na média, bem maiores, segundo a potência instalada, que as demais. A média das potências instaladas das hidrelétricas do setor federal é mais que duas vezes superior à média das públicas estaduais que, por sua vez, é um pouco maior que a média das usinas do setor privado. A energia produzida e o número de funcionários seguem o comportamento da potência instalada. Já a média das alturas de queda das hidrelétricas do setor privado é muito superior às médias das duas subdivisões do setor público.

O setor público foi mais eficiente que o privado. O setor público federal foi o mais eficiente num dos métodos, enquanto o setor público estadual o foi no outro. Este resultado pode indicar 
que as privatizações reduzem a eficiência das usinas hidrelétricas. Porém, isto pode não ser verdadeiro diante das diferentes características das usinas hidrelétricas de cada setor.

Vale destacar a importância da ANEEL como órgão regulador, e do ONS como responsável pela determinação da quantidade de energia produzida de cada hidrelétrica, no acompanhamento da eficiência das usinas hidrelétricas das empresas privatizadas para que não ocorra perda de eficiência nestas unidades produtivas após a privatização, o que poderia levar a uma diminuição da oferta de energia - situação contrária ao objetivo da atual política de privatizações do governo.

\subsubsection{Eficiência por empresa}

As hidrelétricas da amostra pertencem a 12 empresas: 4 de propriedade privada; 5 de propriedade pública estadual; e 3 públicas federais. A discussão centrou-se nas cinco empresas com maior número de hidrelétricas (6 ou mais por empresa).

Em resumo, tem-se que entre as duas empresas públicas federais, a Chesf obteve melhor desempenho que Furnas em ambos os métodos e ainda apresentou o melhor resultado no DEA-C. No âmbito das estaduais, a Cesp foi melhor que a Cemig e, mais ainda, a empresa paulista classificou-se em segundo e primeiro postos, de acordo com o DEA-C e DEA-V, respectivamente, em relação a todas as cinco companhias comparadas. A Light - única privada - obteve a pior classificação no DEA-C, e a segunda pior no DEA-V (Gráfico 1).

\section{Gráfico 1 - Distribuição dos escores de eficiência técnica, segundo a empresa proprietária: mo- delo DEA-V}

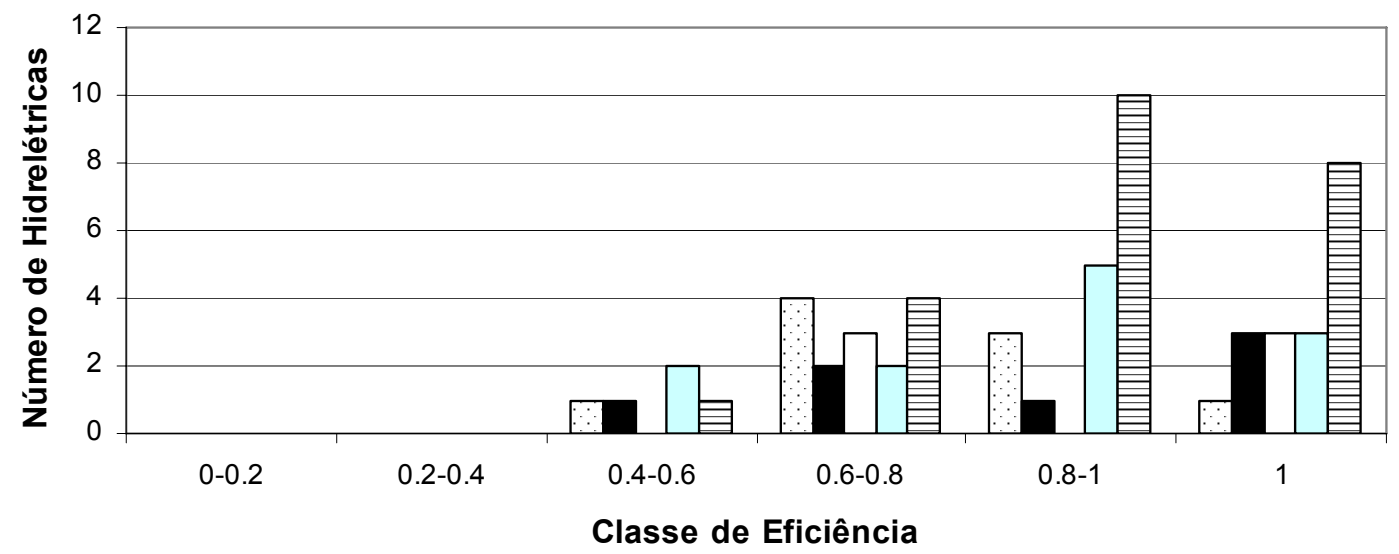

$\square$ Furnas $\square$ Chesf $\square$ Light $\square$ Cemig $\boxminus$ Cesp

Esta última análise comprova a discussão anterior acerca da maior eficiência do setor público, e reforça a necessidade do acompanhamento da ANEEL sobre as hidrelétricas privatizadas, principalmente sobre as hidrelétricas da Cesp, que obtiveram o melhor desempenho geral de eficiência. Vale lembrar que esta empresa foi considerada, no trabalho, como pública estadual (dados de 1998), mas já foi subdividida em três partes, duas das quais passadas à iniciativa privada no ano de 1999, com os nomes de Paranapanema e Tietê. 


\subsubsection{Eficiência e localização (por bacias bidrográficas)}

Das 71 hidrelétricas consideradas, 88,7\% estão localizadas em três divisões de bacias hidrográficas: na bacia do rio Paraná, na bacia do rio São Francisco e na divisão de bacias do Atlântico Leste, onde estão os rios Paraíba do Sul (SP), Doce (MG e ES), Pardo e Jequitinhonha (MG e BA). As discussões seguintes dizem respeito a estas três divisões de bacias.

As hidrelétricas da bacia do rio Paraná foram representadas por 68,2\% de suas unidades, com valores de eficiência acima de 0,6 no DEA-C, e igual porcentual de usinas com escore acima de 0,8, no DEA-V. A bacia do rio São Francisco obteve o porcentual de 57,2\% de suas hidrelétricas com escore acima de 0,6 (no DEA-C) e mesmo porcentual de usinas com escore acima de 0,8, no DEA-V. A divisão de bacia do Atlântico Leste apresentou porcentuais de $25 \%$ e 41,7\%, respectivamente, em relação ao escore de 0,6 (DEA-C) e 0,8 (DEA-V).

A bacia do rio Paraná foi a mais eficiente, seguida da bacia do rio São Francisco e, por fim, do conjunto de bacias do Atlântico Leste. Este resultado tem uma forte conexão com o resultado da eficiência por empresa, já que todas as hidrelétricas da Light, que obteve o pior desempenho de eficiência entre as empresas, estão no conjunto de bacias do Atlântico Leste. Analisando as seis usinas desta bacia que não são de propriedade da Light, têm-se quatro delas com escores abaixo de 0,6 no DEA-C e de 0,8 no DEA-V. Este fato, além de indicar que as hidrelétricas desta bacia são menos eficientes que as demais, sugere que a ineficiência das hidrelétricas da Light pode ser uma conseqüência das características das bacias hidrográficas onde estão localizadas.

\subsubsection{Eficiência e tamanho (potência instalada)}

As hidrelétricas foram divididas em três grupos, de acordo com a potência instalada: pequenas - com potência instalada menor que $300 \mathrm{MW}$; médias - potência instalada entre 300 e $1000 \mathrm{MW}$; e grandes - potência instalada superior a 1000 MW. Para o DEA-C, o escore médio das 30 hidrelétricas classificadas como pequenas foi de 0,578 , o das 20 hidrelétricas médias de 0,830 e o das grandes de 0,717. No DEA-V, os escores médios, na mesma seqüência anterior, foram de: 0,846, 0,830 e 0,785. Considerando como referência os escores de 0,6 (DEA-C) e 0,8 (DEA-V), tem-se que as hidrelétricas médias se mostraram mais eficientes que as demais.

Pelo mesmo critério, as grandes e pequenas se alternaram no ordenamento de desempenho, com as grandes melhor classificadas no método que admite retornos constantes de escala, e as pequenas no de retornos variáveis de escala.

No método de retornos constantes de escala (DEA-C), todas as cinco hidrelétricas que obtiveram escore máximo de eficiência e que, portanto, determinaram a fronteira, têm potência instalada superior a 300 MW. Isto é, a tecnologia da fronteira tida como referência para as demais hidrelétricas é determinada por usinas médias e grandes. Por outro lado, no DEA-V, que admite retornos variáveis de escala, a fronteira representa diversas tecnologias e é determinada por 21 usinas de todas as três classes consideradas de potência instalada. Desta forma, pode-se justificar a ineficiência das “pequenas”, no primeiro método, pelas diferenças entre as tecnologias usadas por estas em relação às hidrelétricas médias e grandes. Além disso, considerando várias tecnologias na construção da fronteira, verifica-se que as "grandes" são mais ineficientes que as demais.

Vale lembrar que a utilização da potência instalada pode indicar a adequação do projeto de uma usina. Verifica-se, por meio da relação da mesma com a quantidade de energia produzida, como a hidrelétrica está utilizando sua capacidade máxima produtiva. 
Apesar das hidrelétricas menos eficientes terem sido as "pequenas", no primeiro caso, e as "grandes”, no segundo, ressalta-se que a escolha da construção de uma usina hidrelétrica não se pauta pelo critério de eficiência técnica ligado à operação abordado neste trabalho.

Para definir a prioridade de projetos leva-se em consideração a escolha da localização da usina, de forma que sua posição permita aproveitar, da melhor maneira possível, o uso da água, por meio de maiores vazões e maiores alturas efetivas, o que acarreta a possibilidade de maior geração de energia, permitindo, assim, uma alta potência instalada.

Normalmente, com a intenção de aproveitar esses melhores lugares de uso da água, são construídas em primeiro lugar as maiores hidrelétricas, até porque projetos dessa magnitude têm um longo alcance, e uma usina ineficiente hoje, em relação ao uso de sua capacidade instalada, pode ser muito eficiente a longo prazo quando a demanda de energia aumentar.

Um outro fator que influencia na construção de uma usina é a distância dos locais potenciais aos grandes centros urbanos, o que pode dar preferência à escolha de uma usina com potência instalada menor ou maior, independente da eficiência técnica que ela terá, pelo fato de minimizar os custos com as redes de transmissão que vão ligar a hidrelétrica aos centros consumidores.

Por isso, esse trabalho não tem o intuito de indicar que tamanho de usina deve ter preferência na ordem de construção das mesmas, ou seja, que tipo de projeto é melhor ou pior para o Brasil. Para este caso, sugere-se a aplicação da metodologia DEA, como fizeram Sant'Anna e Estellita (1998). Contudo, propõe-se a ampliação do trabalho citado, com a consideração de qualquer tipo de usina, e não somente aquelas a fio d'água (que operam sem um reservatório significativo), sendo usadas as diversas variáveis técnicas empregadas naquele trabalho, e mais as seguintes: custos ambientais, que podem ser representados pela dimensão inundada pela água do reservatório de cada usina hidrelétrica, variável que pode ser medida facilmente pela área máxima do espelho d'água dos reservatórios; e ainda os seguintes custos sociais: custo de população deslocada, área agrícola inundada, e o custo das inundações de sítios arqueológicos.

\subsubsection{Eficiência e altura de queda}

Tem-se a seguinte divisão das usinas hidrelétricas, de acordo com a altura de queda: grandes hidrelétricas - com altura de queda superior a 80 metros; médias hidrelétricas - altura de queda entre 40 e 80 metros; e as pequenas - altura de queda inferior a 40 metros. As hidrelétricas de grandes quedas apresentaram o pior desempenho nos dois métodos. Vale destacar o baixo porcentual com escore acima de 0,8 no DEA-V (27,3\%).

Devido à ausência de dados, considerou-se no presente trabalho apenas a altura de queda como variável representativa do uso da água. Para representar este uso, o ideal seria um produto entre a altura efetiva e a vazão turbinada das usinas. Desta forma, o resultado que associa hidrelétricas com elevadas alturas de quedas ao pior desempenho de eficiência pode ser conseqüência de uma associação destas hidrelétricas com uma baixa vazão turbinada, o que faria reduzir o produto destas duas variáveis.

\subsubsection{Eficiência e mão-de-obra}

Dividiram-se as hidrelétricas em 3 categorias, de acordo com número de funcionários (L): usinas com mais de 250 funcionários; usinas com número de funcionários entre 150 e 250; e usinas com menos de 150 funcionários. O destaque na análise da eficiência, segundo a mão-de-obra, foi a categoria intermediária (número de funcionários entre 150 e 250) que obteve o maior porcentual 
de usinas com escore acima de 0,8 , no DEA-V, e o segundo maior porcentual acima de 0,6 , no DEA-C.

As usinas com maior número de funcionários $(>250)$ foram as mais eficientes pelo método DEA-C. No DEA-V, que supõe retornos variáveis de escala, ocorreu uma inversão, sendo as usinas com maior número de funcionários as menos eficientes. Este fato pode, novamente, ser uma conseqüência das condições de retornos de escala para a construção da fronteira.

\section{CONCLusões}

De modo geral, o setor público foi mais eficiente que o privado, embora, como antes destacado, as características das hidrelétricas não permitam inferências quanto às conseqüências das privatizações. Analisando o setor privado e os subsetores públicos - estadual e federal -, constatou-se que o setor público federal foi o mais eficiente em um dos métodos, enquanto o setor público estadual o foi no outro. Entretanto, as hidrelétricas privadas são menores em termos de potência do que as públicas.

$\mathrm{Na}$ análise da eficiência das hidrelétricas de acordo com as empresas proprietárias (para as cinco com maior número de usinas), a Light - única privada - obteve a pior classificação, considerando-se retornos constantes de escala, e a segunda pior, no caso de retornos variáveis de escala. A Cesp foi a empresa de melhor resultado, sendo classificada como mais eficiente no DEA-C e segunda mais eficiente no DEA-V, superando a também estadual Cemig nos dois casos. Entre as federais, a Chesf ficou melhor classificada que Furnas e ainda apresentou o melhor resultado considerando-se retornos constantes de escala.

De acordo com a localização (bacia hidrográfica), observou-se que a bacia do rio Paraná foi a mais eficiente. Em seguida veio a bacia do rio São Francisco e, por fim, o conjunto de bacias do Atlântico Leste, onde estão os rios Paraíba do Sul (SP), Doce (MG e ES), Pardo e Jequitinhonha (MG e BA). Este resultado tem uma forte conexão com o resultado da eficiência por empresa, já que todas as hidrelétricas da Light, que obteve o pior desempenho de eficiência entre as empresas, estão no conjunto de bacias do Atlântico Leste. Este fato sugere que a ineficiência das hidrelétricas da Light pode ser uma conseqüência das características das bacias hidrográficas onde estão localizadas.

No que tange ao tamanho (potência instalada) das usinas hidrelétricas, as médias (potência instalada entre 300 e $1000 \mathrm{MW}$ ) mostraram-se mais eficientes que as demais. As grandes (potência instalada acima de $1000 \mathrm{MW}$ ) e pequenas (potência instalada abaixo de $300 \mathrm{MW}$ ) alternaram-se no ordenamento de desempenho, com as grandes melhor classificadas no método que admite retornos constantes de escala, e as pequenas no de retornos variáveis de escala.

$\mathrm{Na}$ análise de eficiência de acordo com a altura de queda, constatou-se que as hidrelétricas de "grandes quedas" (altura de queda superior a 80 metros) apresentaram o pior desempenho em ambos os métodos. Porém, ressalta-se mais uma vez que devido à ausência de dados considerou-se, no trabalho, apenas a altura de queda como variável representativa do uso da água.

Em relação à mão-de-obra, constatou-se que as usinas com maior número de funcionários (L $>250$ ) foram as mais eficientes pelo método DEA-C. No DEA-V, que supõe retornos variáveis de escala, ocorreu uma inversão, sendo as usinas com maior número de funcionários as menos eficientes. Este fato pode, novamente, ser uma conseqüência das condições de retornos de escala para a construção da fronteira. 
Como conclusão geral em relação à privatização pode-se afirmar que não há elementos para se concluir, com clareza, que necessariamente haverá perda de eficiência uma vez que as características das hidrelétricas públicas e privadas são distintas. A análise mostra que o conjunto das hidrelétricas públicas se apresentou mais eficiente que o privado, mas não se deve tirar conclusões apressadas acerca deste resultado, devido à heterogeneidade das condições. Por outro lado, vale destacar o papel essencial da ANEEL como órgão regulador, e do ONS, como responsável pela determinação da quantidade de energia produzida, no acompanhamento das usinas privatizadas para que não ocorra perda de eficiência nestas unidades produtivas após a privatização.

\section{REFERÊNCIAS BIBLIOGRÁFICAS}

Acioli, J. L. Fontes de energia. Brasília: Editora Universidade de Brasília, 1994.

Aigner, D. J.; Chu, S. F. Estimating the industry production function. American Economic Review, v. 58, n. 4, p. 826-839, September 1968.

ANEEL - Agência Nacional de Energia Elétrica. www.aneel.gov.br, 2000.

Banker, R. D.; Charnes, A.; Cooper, W. W. Some models for estimating technical and scale inefficiencies in data envelopment analysis. Management Science, v. 13, p. 1078-1092, Sept. 1984.

Charnes, A.; Cooper, W. W.; Rhodes, E. Measuring the efficiency of decision making units. European Journal of Operational Research, 2, p. 429-444, 1978.

CHESF - Companhia Hidrelétrica do São Francisco. www.chesf.gov.br, 2000.

Coelli, T. A guide to DEAP Version 2.1: A data envelopment analysis (computer) program. Austrália: University of New England, 1996.

ELETROBRÁS, Rio de Janeiro. Séries 1999; Séries econômico-financeiras de empresas de energia elétrica, demonstrações de 31/ 12/ 98. Rio de Janeiro, 1999.

ELETROBRÁS, 2000. Plano decenal de energia 1999/2008. www.eletrobras.gov.br, 2000.

Farrell, M. J. The measurement of productive efficiency. Journal of The Royal Statistical Society, v. 125, p. 252-267, 1957.

Fried, H. O.; Lovell, C. A. K.; Schmidt, S. S. The measurement of efficiency of production. Oxford: Oxford University Press, 1993.

Gasparini, C. E. Uma análise da eficiência na provisão de serviços públicos municipais no estado de Pernambuco. 2000. 103p. Dissertação (Mestrado), Universidade Federal de Pernambuco, Recife.

IFE - Informe Eletrônico. Disponível em: www.provedor.nuca.ie.ufrj.br/eletrobras.com.br, 2000.

Leite, A. D. A energia do Brasil. Rio de Janeiro: Nova Fronteira, 1997.

Mariano, J. L. A eficiência dos colonos na agricultura irrigada no Vale do São Francisco: uma análise comparativa dos modelos de fronteira paramétrica e não paramétrica. 1999. 147p. Tese (Doutorado), Universidade Federal de Pernambuco, Recife.

Mas-Colell, A.; Whinston, M. D.; Green, J. R. Microeconomic theory. New York/Oxford: Oxford University Press, 1995.

ONS, 2000. Planejamento anual da operação energética; sistema interligado nacional. Abril de 2000.

Pires, J. C. L. Características básicas do setor elétrico brasileiro, antecedentes e motivação das reformas constitucionais. Revista do BNDES, Rio de Janeiro, v. 6, p. 137-168, dezembro 1999.

Ramos, F. S.; Sousa, M. C. S. Eficiência técnica e retornos de escala na produção de serviços públicos municipais: o caso do Nordeste e do Sudeste brasileiros. Revista Brasileira de Economia, v. 53, p. 433-462, out./dez. 1999. 
Sant'anna, L. A. F. P.; Estellita Lins, M. Análise da eficiência de hidrelétrica a fio d'água. In: SBPO, Anais, 1998.

SIPOT - Sistema de Informação do Potencial Hidrelétrico Brasileiro, 1998. Disponível em: www.ele$\underline{\text { trobras.com.br. }}$ 